\title{
IMPLEMENTASI ARTIFICIAL INTELLIGENCE PADA SISTEM PENGAWASAN PASIEN RUMAH SAKIT
}

\author{
Ondra Eka Putra, S.Kom., M.Kom. \\ email: ondraekaputra17@gmail.com
}

\begin{abstract}
This study was conducted to create a system that can megawasi and detect temperature, noise, patients down from the bed in the patient's room in the hospital. This system is done by designing to create and implement system components including Arduino Mega as process controller, switch as emergency calling, LED and LCD to notify detected information, DHT11 sensor as temperature sensor, Sound sensor micropone as noise sensor, sensor loadcell as sensor weight and MP3 module as a sound notification, location detected in patient room in hospital. The results showed that the tool is made to function properly and can be used directly in place that requires.
\end{abstract}

Keyword: $\quad$ Switch, Surveillance, Mega Arduino, LED, Temperature, and LCD

\section{PENDAHULUAN}

\section{Latar Belakang Masalah}

Pada umumnya tidak semua rumah sakit menggunakan pengawasan yang dilakukan dari jarak jauh. Rumah sakit masih melakukan pengawasan pasien secara manual dengan memasuki ruangan pasien satu persatu. Hal ini tentunya kurang efektif, karna di sebuah rumah sakit memiliki banyak kamar pasien yang harus terus diawasi. Apabila ada yang membutuhkan bantuan secara cepat maka akan sulit jika tidak ada pengwasan secara instensif.

Semua pasien membutuhkan perawatan yang cepat dan tepat. Pasien yang tidak ditunggui kemudian membutuhkan bantuan perawat seringkali mengalami kesulitan dalam memanggil perawat untuk datang secepat mungkin ke ruangan dimana pasien tersebut berada dengan perkembangan teknologi pada saat ini banyak perawat dapat lebih mudah dalam pengawasan pasien rumah sakit dengan memanfaatkan komputer dan Arduino Mega sebagai pusat kendali dalam sebuah sistem akan dapat lebih mudah dalam pengendalian komponen yang akan digunakan dan kenyamanan dalam ruangan yang ber-AC memang sangat diinginkan oleh orang-orang pada zaman sekarang. Namun sebaliknya, suhu yang dingin saja ternyata tidak cukup untuk memenuhi kebutuhan didalam tubuh manusia, karena perlu adanya keseimbangan antara suhu dingin dan suhu panas. Suhu dingin dan suhu panas ini berkisar antara $27^{\circ} \mathrm{C}-30^{\circ} \mathrm{C}$ yaitu suhu normal yang dibutuhkan tubuh manusia agar selalu merasa nyaman.

Pada ruangan pasien rumah sakit seringkali tidak terkontrolnya kondisi suhu ruangan, kebisingan ruangan dan pasien yang melanggar anjuran dokter. Hal ini dikarenakan beberapa faktor seperti perawat tidak ada di ruangan pasien, jauhnya jarak antara ruangan pasien dengan ruangan perawat, serta susahnya pengawasan pasien dengan mengatur ketenangan dan temperatur suhu dalam ruangan pasien agar tetap nyaman didalam ruangan. Jika kondisi ruangan pasien nyaman maka akan lebih cepat pasien sembuh dari penyakit yang diderita.

Diterima Redaksi : 10-9-2020| Selesai Revisi : 10-10-2020| Diterbitkan Online : 11-10-2020 


\section{Perumusan Masalah}

Berdasarkan permasalahan yang ada, maka peneliti membuat perumusan masalah yaitu bagaimana dengan sistem pengawasan pasien ruangan rumah sakit dapat memudahkan dalam pemanggilan darurat perawat dan pengontrolan kondisi pasien rumah sakit.

\section{Tujuan Penelitian}

Adapun tujuan penelitian yang ingin dicapai adalah Membuat suatu alat yang dapat mempermudah pasien dalam pemanggilan darurat perawat dan pengontrolan kondisi pasien rumah sakit.

\section{LANDASAN TEORI}

\section{Konsep Dasar Sistem}

Sistem adalah entitas atau satuan yang terdiri dari dua atau lebih komponen atau subsistem (sistem yang lebih kecil) yang saling terhubung dan terkait untuk mencapai suatu tujuan.

Sistem ini terdiri dari komponen atau elemen yang saling terkait untuk mencapai tujuan tertentu, diantaranya kegiatan ataupun pekerjaan yang telah dibentuk. Pada umumnya sistem mempunyai input yang dibutuhkan sistem untuk proses dan akan menghasilkan keluaran atau output berupa informasi. Untuk lebih jelasnya dapat dilihat pada gambar 2.1 dibawah ini :

\section{Gambar 1 Model sistem}

\section{Context Diagram}

Context diagram merupakan diagram yang menggambarkan interaksi sistem dengan penggunanya. Pengguna memasukan data dan menerima informasi dari sistem sedangkan sistem mengolah data yang diterima dan menampilkannya sebagai data yang lebih berguna bagi pemakainya.Untuk lebih jelasnya dapat dilihat pada tabel 1 dibawah ini :

Tabel 1 Simbol dari Context Diagram

\begin{tabular}{|c|c|}
\hline Simbol Contecxt Diagram & Arti Khusus \\
\hline & Sistem \\
\hline
\end{tabular}

Diterima Redaksi : 10-9-2020| Selesai Revisi : 10-10-2020| Diterbitkan Online : 11-10-2020 


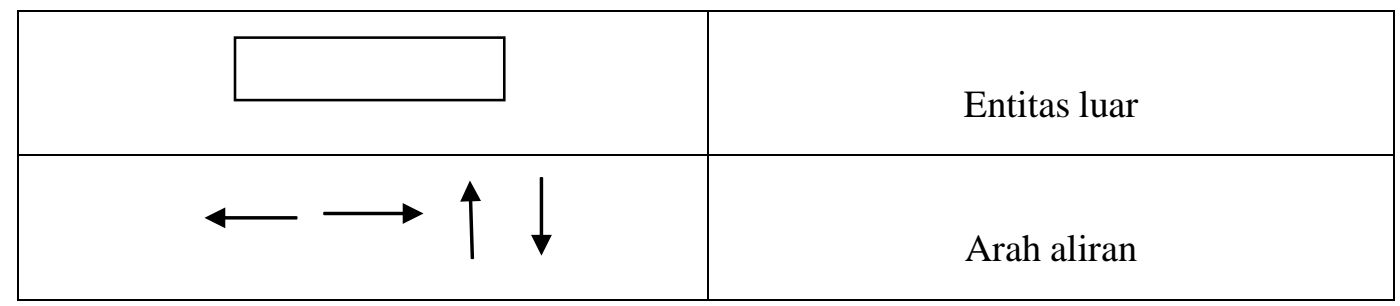

\section{Data Flow Diagram}

Data flow diagram (DFD) adalah suatu diagram yang berisi simbol-simbol grafis yang digunakan untuk menggambarkan aliran data yang ada dalam sebuah system. DFD menggambarkan fungsi-fungsi yang dimiliki oleh sistem yang akan dibangun. Berikut ini adalah komponen yang digunakan dalam pembuatan suatu context diagram dan DFD dari rancangan sistem yang dibahas dalam penulisan skripsi. Untuk lebih jelasnya dapat dilihat pada tabel 2 dibawah ini :

Tabel 2 Simbol dari Data Flow Diagram

\begin{tabular}{|c|c|}
\hline Simbol DFD & Arti Khusus \\
\hline & Proses atau fungsi sistem \\
\hline & Entitas luar \\
\hline & Simpanan data \\
\hline$\longrightarrow \longrightarrow$ & Arah aliran \\
\hline
\end{tabular}

\section{Flowchart Program}

Flowchart atau bagan alir adalah suatu bagan yang berisi simbol-simbol grafis yang menunjukkan arah aliran kegiatan dan data-data yang dimiliki program sebagai suatu proses eksekusi. Bagan-bagan yang mempunyai arus yang menggambarkan langkah-langkah penyelesaian suatu masalah. Merupakan cara penyajian dari suatu algoritma. Untuk lebih jelasnya dapat dilihat pada tabel 3 dibawah ini :

\section{Tabel 3 Simbol-Simbol Standar Dalam Flowchart}

\begin{tabular}{|c|c|}
\hline $\begin{array}{c}\text { Bentuk-bentuk bagan dalam } \\
\text { flowchart }\end{array}$ & Arti khusus \\
\hline$\square$ & Memulai atau mengakhiri program \\
\hline
\end{tabular}

Diterima Redaksi : 10-9-2020| Selesai Revisi : 10-10-2020| Diterbitkan Online : 11-10-2020 


\begin{tabular}{|c|c|}
\hline & Proses (menulis atau menjalankan) program \\
\hline & Masukan atau keluaran \\
\hline & Pengambilan keputusan atau pengujian program \\
\hline
\end{tabular}

\section{Sistem Kontrol}

Pengontrolan otomatis adalah pengontrolan yang dilakukan oleh mesin-mesin atau peralatan yang bekerja secara otomatis dan operasinya di bawah pengawasan manusia. Sesuai dengan fungsi pengontrolan secara menyeluruh, maka komponen sistem pengontrolan dapat dibagi atas 4 bagian yaitu : sensor (Transducer), pemproses, penggerak dan penguat. Sistem kontrol berdasarkan cara kerjanya dapat dibagi menjadi dua bagian, yaitu sistem kontrol loop terbuka dan tertutup.

\section{A. Sistem Loop Terbuka}

Pada sistem kendali loop terbuka, hasil keluaran tidak mempunyai pengaruh terhadap aksi kontrol dengan kata lain pada sistem kendali ini keluaran tidak dapat digunakan sebagai perbandingan atau umpan balik dengan masukan system.

Pada sistem kendali loop terbuka, hasil keluaran tidak mempunyai pengaruh terhadap aksi kontrol dengan kata lain pada sistem kendali ini keluaran tidak dapat digunakan sebagai perbandingan atau umpan balik dengan masukan sistem. Sistem kendali loop terbuka tidak mampu membandingkan keluaran untuk dijadikan acuan dari masukan sehingga setiap acuan masukan terhubung dengan kondisi operasi tertentu, sebagai akibatnya adalah ketepatan dari sistem tergantung dari tingkat keakuratan kalibrasi sistem. Gangguan-gangguan yang ada adalah suatu sinyal yang cendrung akan merugikan dan akan memberi pengaruh buruk pada 
nilai keluaran sistem tersebut, baik gangguan yang terbangkitkan dari dalam sistem, maupun yang datang dari luar sistem. Sistem kendali terbuka dapat digunakan hanya jika hubungan antara masukan dan keluaran diketahui secara pasti dan tidak terdapat gangguan internal maupun eksternal.

Untuk lebih jelasnya dapat dilihat pada diagram blok dari sistem pengendalian loop terbuka pada gambar 2 dibawah ini :

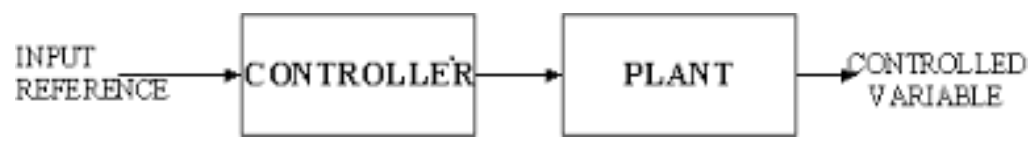

\section{Gambar 2 Diagram Blok Kendali Loop Terbuka}

Pada kendali loop terbuka keluarannya tidak dapat dipergunakan sebagai perbandingan umpan balik dengan masukan, jadi untuk setiap masukan acuan berhubungan dengan kondisi operasi tertentu.

\section{B. Sistem Loop Tertutup}

Sistem yang dapat memanfaatkan keluaran sebagai acuan dari masukan suatu sistem disebut sebagai sistem kendali loop tertutup atau sering dikatakan sebagai sistem kontrol umpan balik. Sederhananya sistem kontrol umpan balik dan sistem kendali loop tertutup selalu berarti penggunaan aksi kontrol umpan balik untuk mengurangi kesalahan system.

Sistem yang dapat memanfaatkan keluaran sebagai acuan dari masukan suatu sistem disebut sebagai sistem kendali loop tertutup atau sering dikatakan sebagai sistem kontrol umpan balik. Sederhananya sistem kontrol umpan balik dan sistem kendali loop tertutup selalu berarti penggunaan aksi kontrol umpan balik untuk mengurangi kesalahan system. Untuk lebih jelasnya dapat dilihat pada gambar 3 dibawah ini :

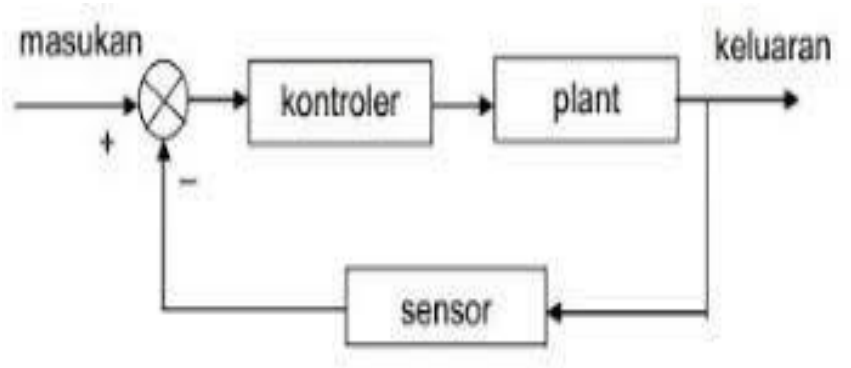

\section{Gambar 3 Diagram Blok Kendali Loop Tertutup}

\section{Sensor DHT 11}

DHT11 adalah sensor Suhu dan Kelembaban, dia memiliki keluaran sinyal digital yang dikalibrasi dengan sensor suhu dan kelembaban yang kompleks. Teknologi ini memastikan 
keandalan tinggi dan sangat baik stabilitasnya dalam jangka panjang. mikrokontroler terhubung pada kinerja tinggi sebesar 8 bit. Sensor ini termasuk elemen resistif dan perangkat pengukur suhu NTC. Memiliki kualitas yang sangat baik, respon cepat, kemampuan anti-gangguan dan keuntungan biaya tinggi kinerja.

Setiap sensor DHT11 memiliki fitur kalibrasi sangat akurat dari kelembaban ruang kalibrasi. Koefisien kalibrasi yang disimpan dalam memori program OTP, sensor internal mendeteksi sinyal dalam proses, kita harus menyebutnya koefisien kalibrasi. Sistem antarmuka tunggal-kabel serial terintegrasi untuk menjadi cepat dan mudah. Kecil ukuran, daya rendah, sinyal transmisi jarak hingga 20 meter, sehingga berbagai aplikasi dan bahkan aplikasi yang paling menuntut. Produk ini 4-pin pin baris paket tunggal. Koneksi nyaman, paket khusus dapat diberikan sesuai dengan kebutuhan pengguna. Bentuk fisik dari sensor DHT11 dapat dilihat pada gambar 4 dibawah ini :

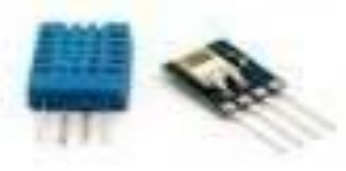

\section{Gambar 4 Sensor DHT11}

Spesifikasi sensor DHT 11 :

1. Catu daya : $3 \mathrm{VDC}-5,5 \mathrm{VDC}$.

2. Antarmuka : 1-wire.

3. Range $:$ humidity $=20-90 \%$ RH, Temp $=0-50$ derajat Celcius.

4. Resolusi : $1 \%$ RH (humidity) dan 0,1C (temp).

\section{METODOLOGI PENELITIAN}

Kerangka kerja penelitian merupakan tahap awal dari sebuah proses penelitian yang akan kita lakukan yang bertujuan menggambarkan proses dari sistem penelitian agar dapat membatasi supaya tidak melenceng dari konsep yang ingin dibuat. Didalam kerangka kerja penelitian kita menentukan strategi apa yang dilakukan agar kita dapat mengerti apa yang menjadi tujuan dari penelitian ini. Didalam kerangka kerja penelitian ini akan digambarkan tahap-tahap dari sebuah penelitian untuk mempermudah langkah-langkah dari pembuatan alat yang akan dibuat, Berikut langkah-langkah penelitian pada gambar 5 dibawah ini. 


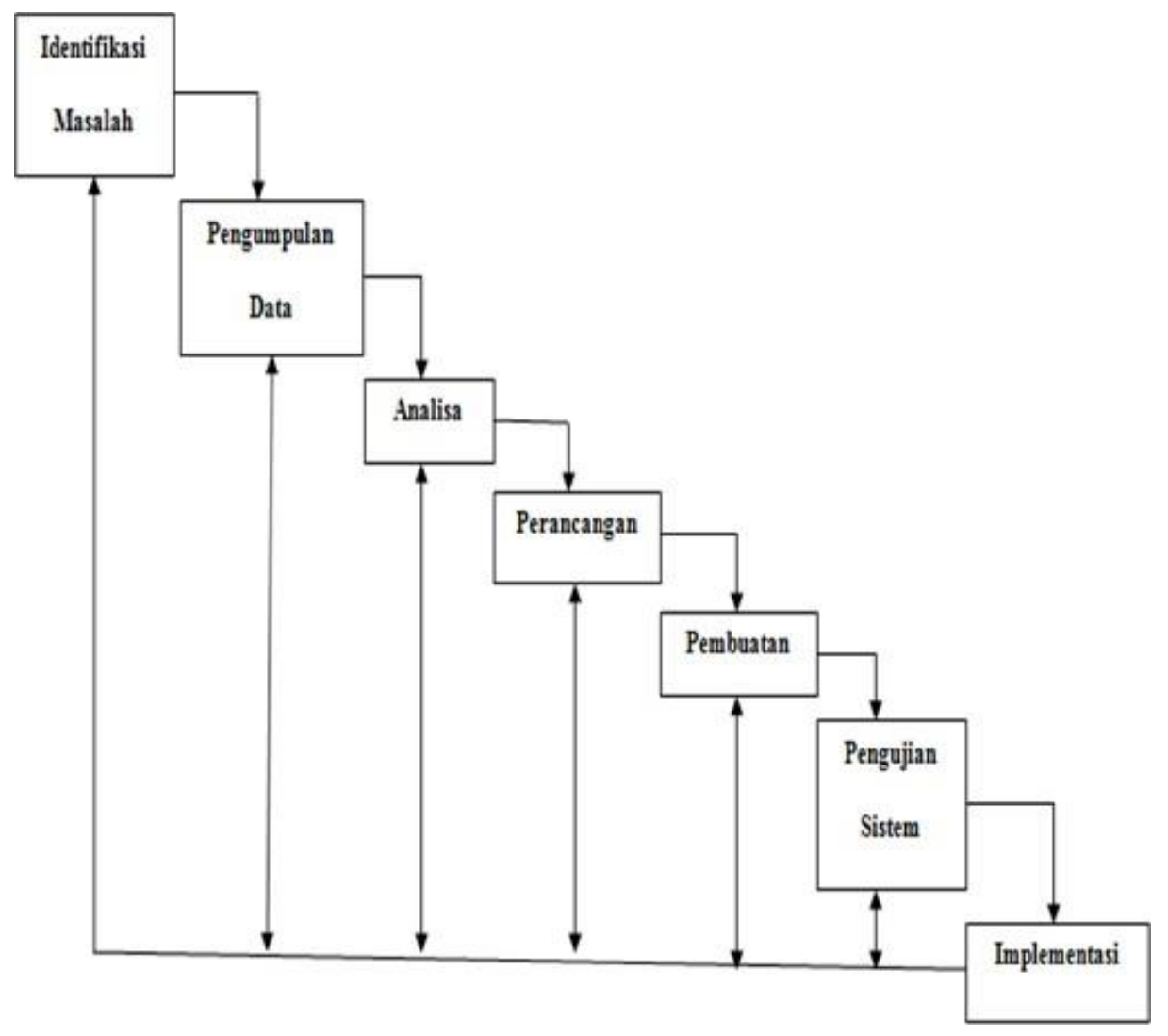

\section{Gambar 5 Kerangka Penelitian}

\section{ANALISA DAN HASIL}

\section{Context Diagram Sistem}

Sub bab ini merupakan penjabaran setiap external entity secara keseluruhan yang digambarkan melalui context diagram. Context diagram merupakan pendefenisian terhadap sistem yang akan dirancang yang bersifat menyeluruh. Context diagram ini digunakan untuk memudahkan dalam proses penganalisaan sistem yang dirancang secara keseluruhan.

Context diagram berfungsi sebagai media, yang terdiri dari suatu proses dan beberapa buahexternal entity. Context diagram yang dimaksud dapat dilihat pada gambar 6 . 


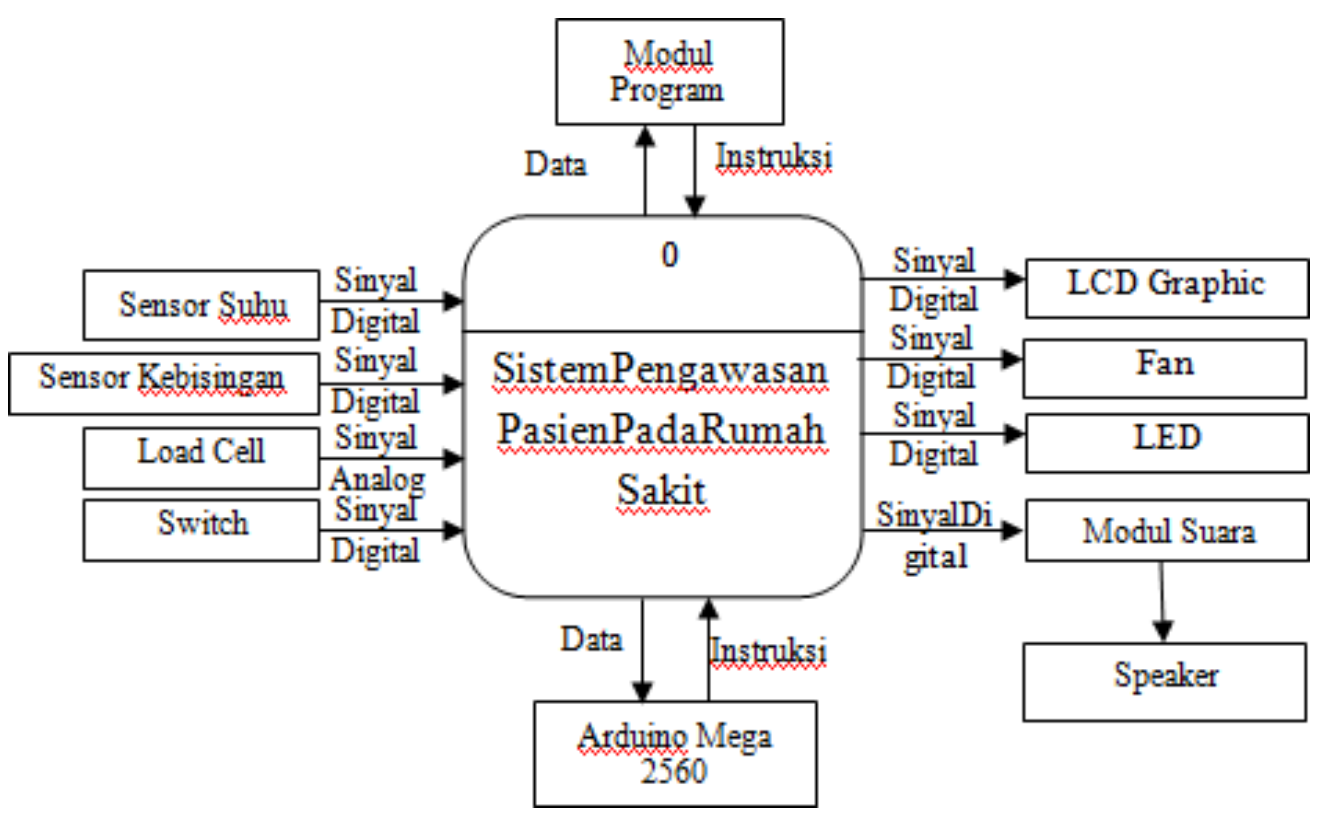

Gambar 6 Context Diagram Sistem

\section{Data Flow Diagram Level 0 Sistem}

Mengacu pada context diagram di atas, untuk mengetahui aliran data dalam system ini dapat dilihat pada Data Flow Diagram Level 0 di bawah. Data Flow Diagram ini merupakan uraian lebih terperinci dari 48ystem yang dirancang. Adapun bentuk data flow diagram level 0 tersebut dapat dilihat pada gambar 7 berikut ini : 


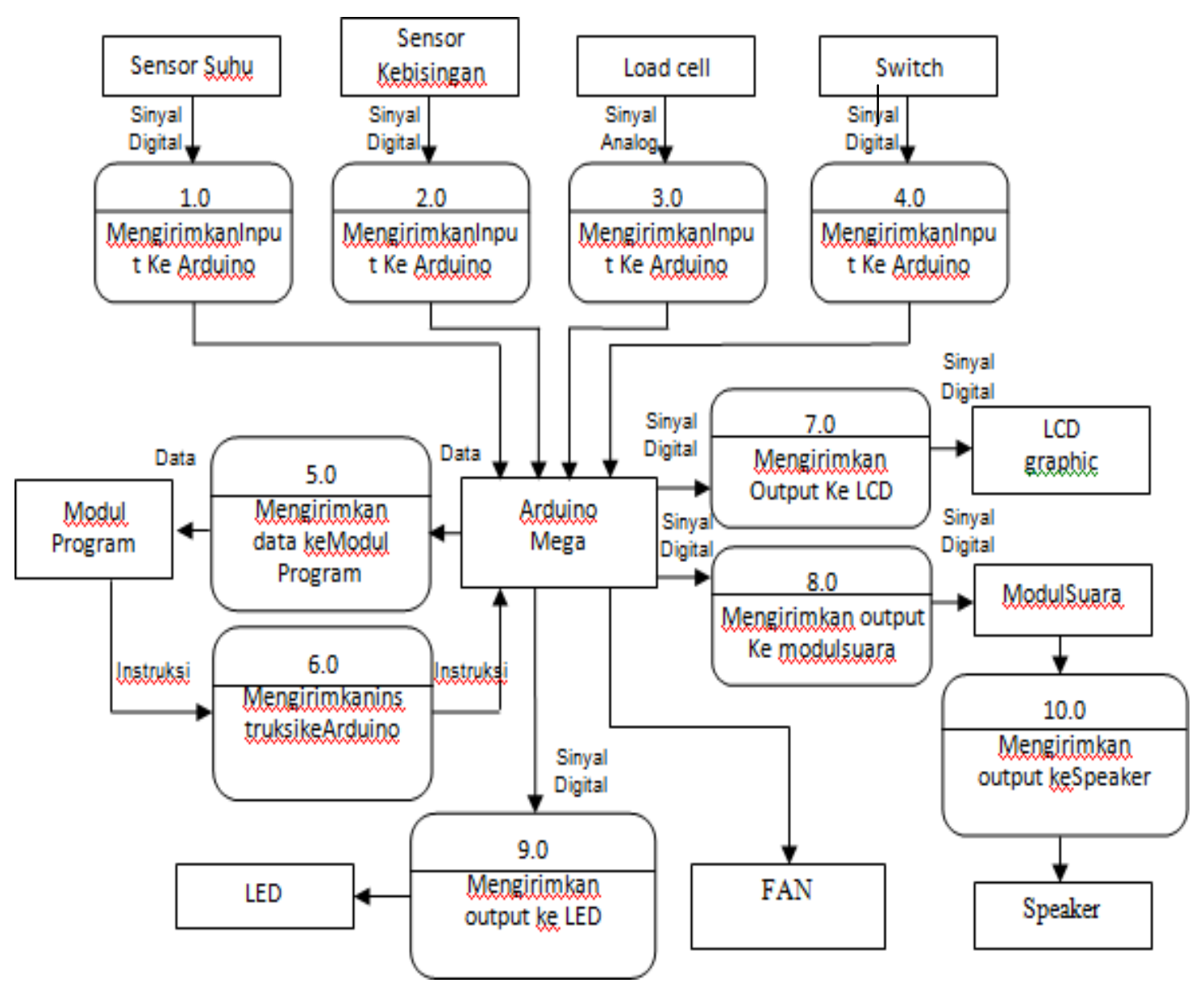

\section{Gambar 7 Data Flow Diagram Sistem}

Pada Data Flow Diagram Level 0 di atas terdapat sepuluh sub proses. Adapun prosesproses tersebut dapat diuraikan sebagai berikut :

1. Sensor suhu mendeteksi perubahan suhu dan mengirimkan input kearduino (1.0).

2. Sensor kebisingan mendeteksi kebisingan dan mengirimkan data kearduino (2.0).

3. Loadcell mendeteksi berat kasur pasien dan mengirimkan input kearduino (3.0).

4. Switch sebagai input tombol bantuan bagi pasien yang mengirimkan input kearduino (4.0).

5. Arduino menerima input dan mengirimkan data kemodul program untuk di proses (5.0).

6. Modul program melakukan pemrosesan data dan menghasilkan instruksi-instruksi yang kemudian dikirim kembali ke arduino (6.0).

7. Arduino memberikan output ke LCD graphic sebagai tampilan informasi system (7.0).

8. Arduino memberikan output kemodul suara jikaterjadi kejaganggalan pada kamar pasien (8.0).

9. Arduinomemberikan output ke LED sebagai indicator system (9.0).

\section{PENGUJIAN SISTEM}

Diterima Redaksi : 10-9-2020| Selesai Revisi : 10-10-2020| Diterbitkan Online : 11-10-2020 
Program yang disimpan dalam Arduino Mega adalah berupa instruksi-instruksi pembacaan input. Selanjutnya Arduino Mega akan memproses berdasarkan program.. Seluruh sistem kendali dipegang sepenuhnya oleh Arduino Mega berdasarkan program yang tersimpan dalam Arduino Mega.

Pengujian dari sistem ini dapat dilakukan dengan langkah-langkah sebagai berikut:

1. Untuk mengaktifkan sistem pengguna harus menekan tombol switch. Lebih jelasnya dapat dilihat pada gambar berikut ini.

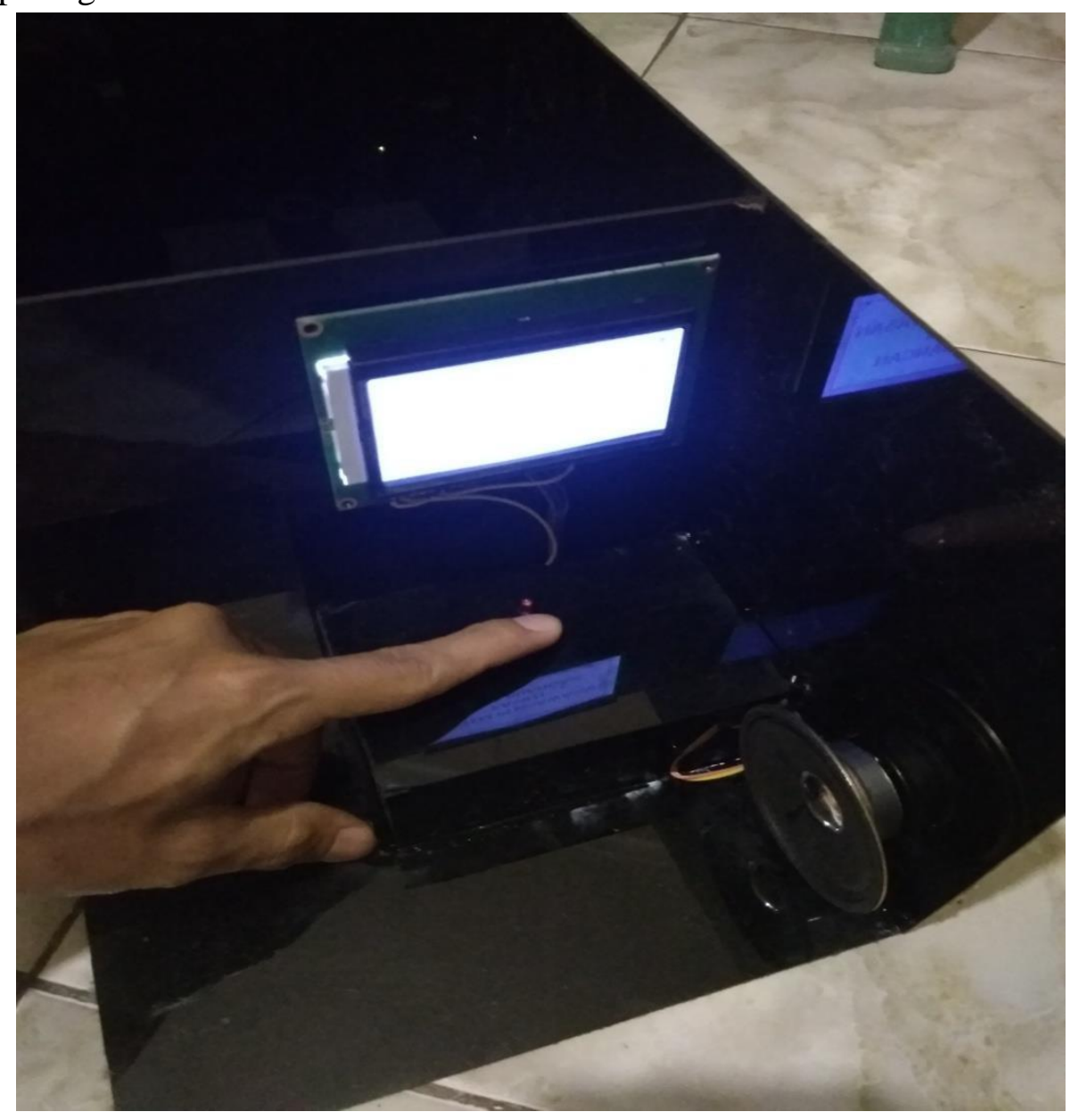

Gambar 8 Pengaktifan sistem

2. Setelah sistem aktif maka sensor suhu, sensor kebisingan dan loadcell akan melakukan pembacaan. Hasil pembacaan dari sensor tersebut akan ditampilkan pada LCD, jelasnya pada gambar berikut ini. 


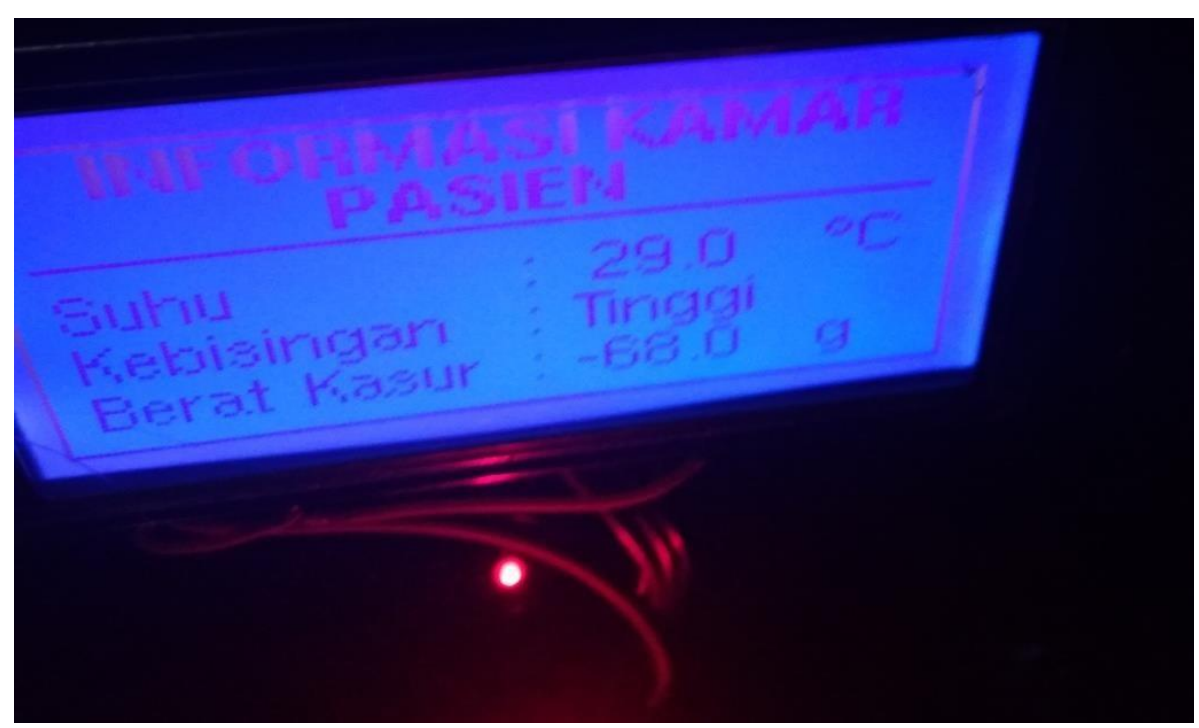

\section{Gambar 9 Hasil Pembacaan Dari Sensor}

3. Jika sistem mendeteksi suhu melebihi $30^{\circ} \mathrm{C}$ maka system akan mengeluarkan suara pemberitahuan suhu kamar naik dan LED indikator akan hidup, lebih jelasnya pada gambar di bawah ini.

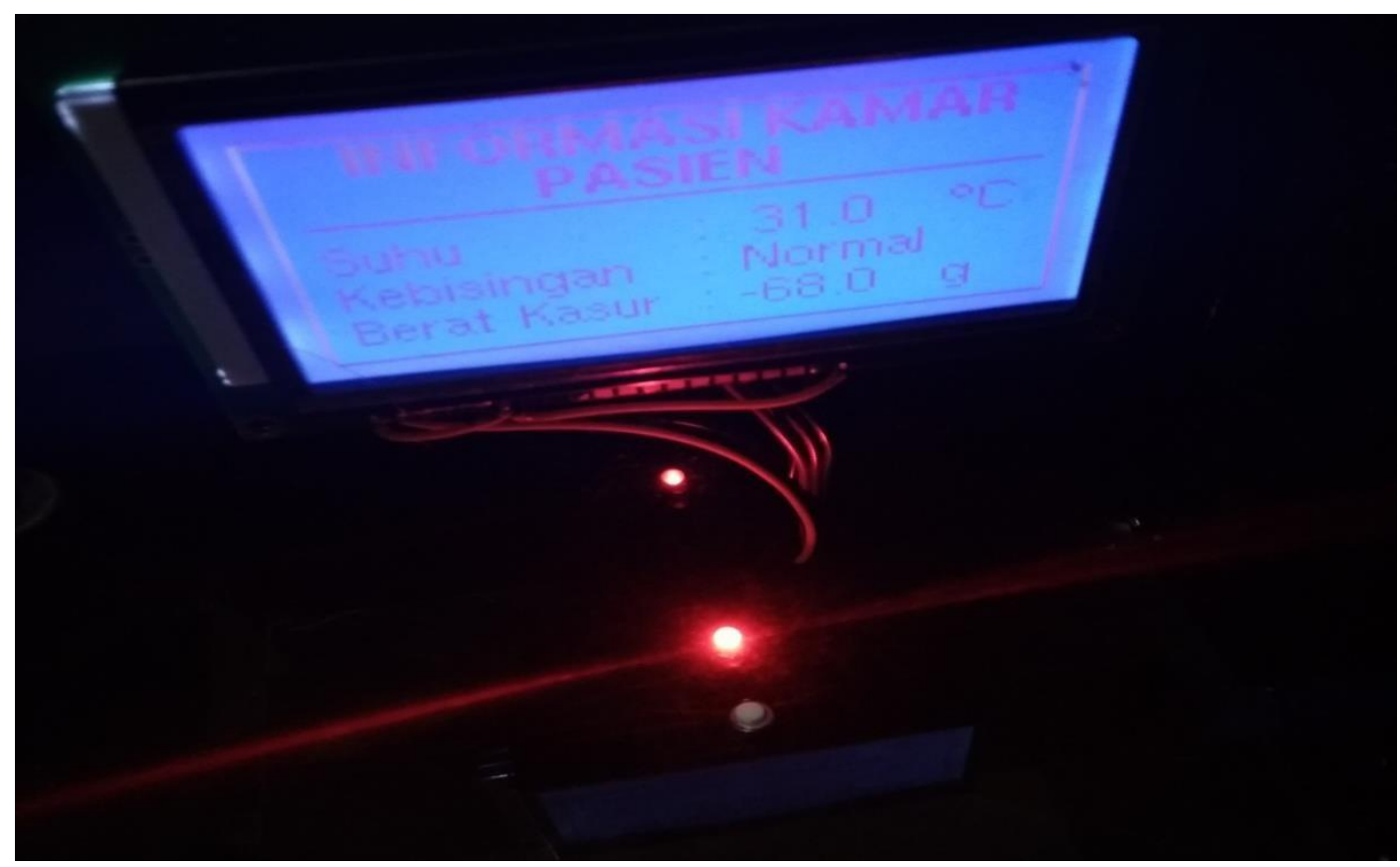

Gambar 10 Pemberitahuan Suhu Ruangan Naik

4. Jika system mendeteksi kebisingan meningkat maka system akan mengeluarkan suara kebisingan pada ruangan pasien melebihi batas dan LED indikator akan hidup,lebih jelasnya pada gambar dibawah ini. 


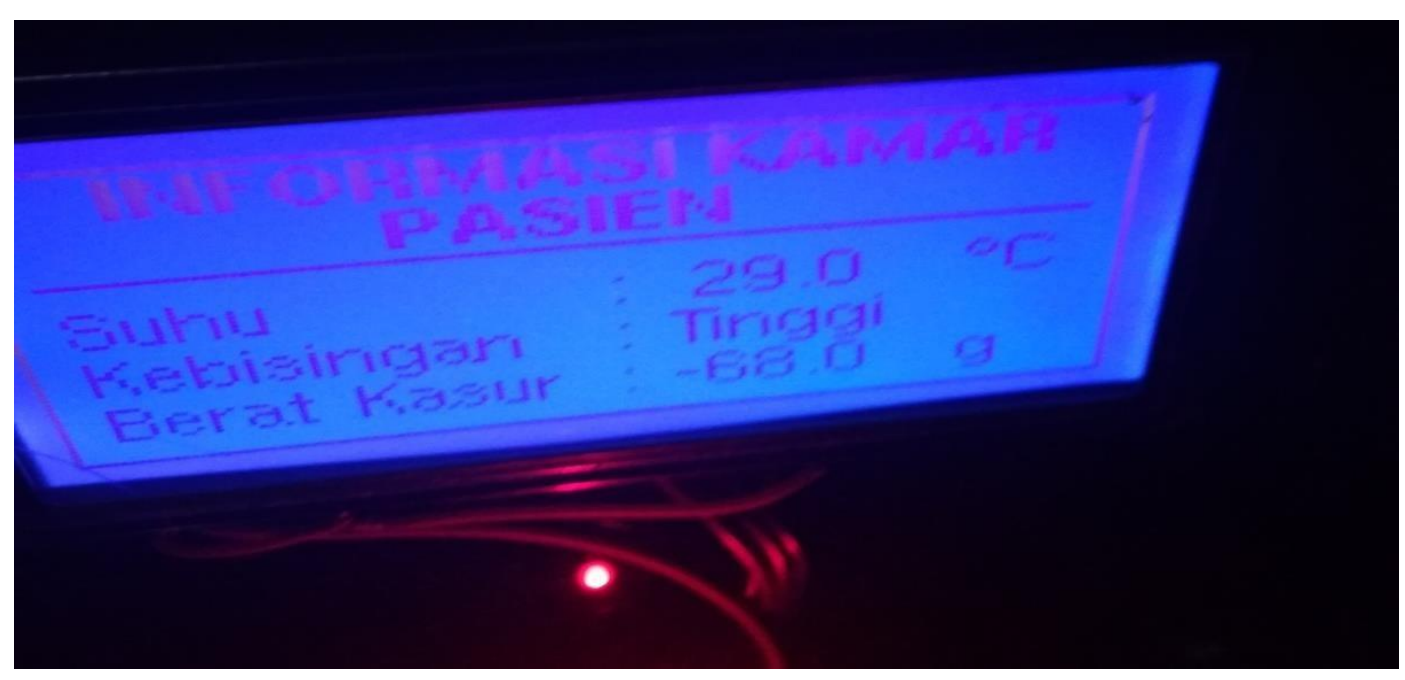

\section{Gambar 11 Pemberitahuan Pendeteksian Kebisingan}

5. Jika system menbeteksi berat tempat tidur berkurang maka system akan mengeluarkan suara pasien meninggalkan tempat tidur dan LED indikator akan hidup, lebih jelasnya pada gambar dibawah ini.

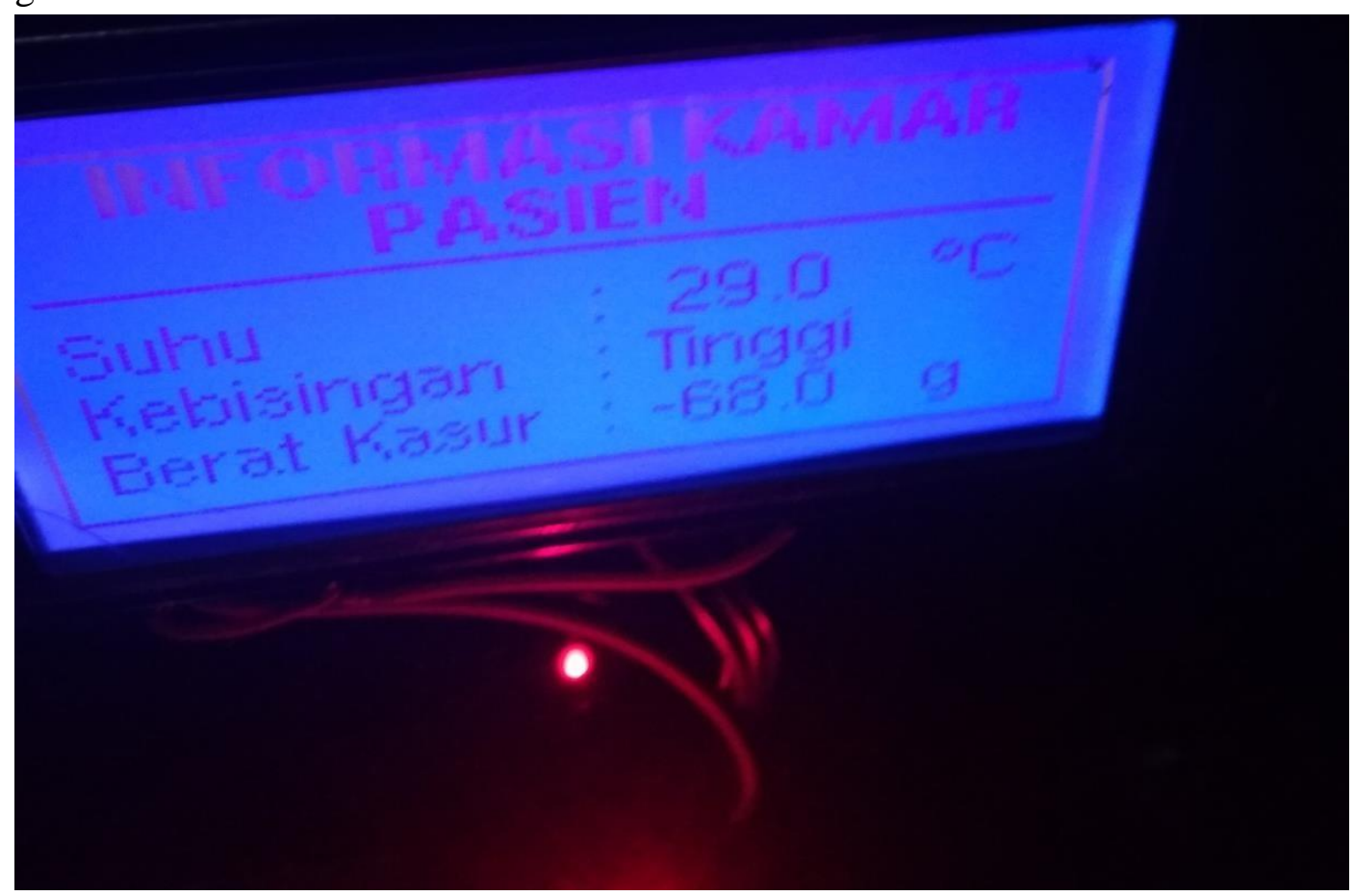

Gambar 12 Pemberitahuan Berat Kasur Berkurang

6. Jika pasien menekan tombol bantuan maka system akan mengeluarkan suara pasien memerlukan bantuan dan LED indikator akan hidup, lebih jelasnya pada gambar dibawah ini. 


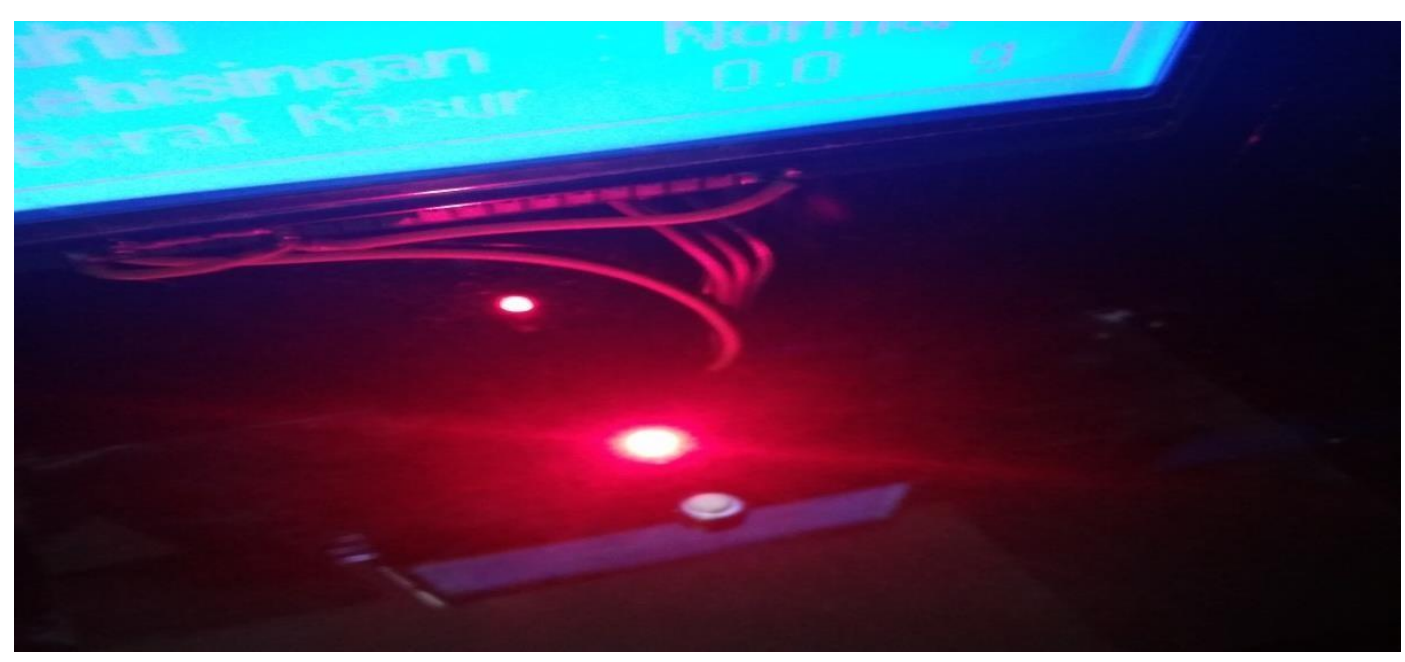

\section{KESIMPULAN}

\section{Gambar 13 Pemberitahuan Darurat}

Adapun kesimpulan yang dapat diambil dari hasil pengujian adalah :

1. Switch dapat bekerja dengan baik dalam pemanggilan perawat.

2. Sensor DHT11 dapat bekerja dengan baik dalam mendeteksi suhu pada ruangan.

3. Sensor sound microphone dapat bekerja dengan baik dalam mendeteksi tingkat kebisingan.

4. Modul mp3 dapat memberikan indicator system dengan baik sesuai dengan kondisi yang telah ditentukan.

5. LCD 128X64 dapat menampilkan hasil pengukuran temperatur suhu dan kebisingan ruangan.

6. Loadcell dapat bekerja dengan baik saat mendeteksi berat pada tempat tidur pasien.

\section{DAFTAR PUSTAKA}

[1] Mujilan, Agustinus. 2013. Analisis dan Perancangan Sistem. Madiun: Universitas Widya Mandala

[2] Yakub. 2012. Pengantar Sistem Informasi. Yogyakarta: Graha Ilmu

[3] Suarga. 2012. Algoritma dan Pemrograman. Yogyakarta: Andi

[4] ETP, Lussiana, dkk. 2011. Mekatronika. Gunadarma University

[5] Andrianto, Heri. 2015. Pemograman Mikrokontroler Atmegal6 MenggunakanBahasa C. Bandung: Informatika

[6] Nalwan, Andi. 2012. Teknik Rancang Robot. Yogyakarta: Andi

[7] Syam, Rafiuddin. 2013. Dasar Dasar Teknik Sensor. Makassar: Fakultas Teknik Universitas Hasanuddin

[8] Setiawan, Afrie. 2011. 20 Aplikasi Mikrokontoler Atmega8535 \& Atmegal6 menggunakan $B A S C O M-A V R$. Yogyakarta: Andi

[9] Ermanto \& Emidar. 2012. Pengembangan Kepribadian di Perguruan Tinggi. Padang: UNP Press 
Jurnal Teknologi, Vol. 10, No.02, Oktober2020, ISSN : 2301-4474, e-ISSN : 2541-1535

Copyright@2020by LPPM UPI YPTK Padang

[10] Arifin, S dan Wicaksono, A.A. 2014. Rancang Bangun Robot Otomatis Loy Krathong Berbasis Mikrokontroler Atmega128 Pada Kasus KRI 2011. Jurnal Ilmiah Teknologi dan Informasi Asia. 8 (1). 37-47 